\title{
Daytime Effect of Monochromatic Blue Light on EEG Activity Depends on Duration and Timing of Exposure in Young Men
}

\author{
Irena Iskra-Golec ', Krystyna Golonka ${ }^{2}$, Miroslaw Wyczesany ${ }^{3}$, Lawrence Smith ${ }^{4}$, \\ Patrycja Siemiginowska ${ }^{2}$, and Joanna Wątroba ${ }^{2}$
}

\author{
${ }^{1}$ SWPS University of Social Sciences and Humanities, Faculty in Poznań, Poland \\ ${ }^{2}$ Institite of Applied Psychology, Jagiellonian University, Kraków, Poland \\ ${ }^{3}$ Psychophisiology Laboratory, Institute of Psychology, Jagiellonian University, Kraków, Poland \\ ${ }^{4}$ Department of Psychology, University of Leeds, Leeds, UK
}

ABSTRACT

Growing evidence suggests an alerting effect of monochromatic blue light on brain activity. Little is known about the moderation of those effects by timing and duration of exposure. The present electroencephalography (EEG) study examined such moderations on delta, theta, alpha1, alpha2, and beta EEG bands. A counterbalanced repeated-measures design was applied. The 16-hr daytime period was divided into three sessions: 07:00-12:20, 12:20-17:40, and 17:40-23:00 (timing of exposure). Two light conditions comparable in luminance but differing in wavelength were applied, namely polychromatic white light and monochromatic blue light $(460 \mathrm{~nm})$. There were two durations of exposure - the shorter one lasting $30 \mathrm{~min}$ and the longer one lasting $4 \mathrm{hrs}$. Thirty male students participated in the study. Four factors analyses of variance (ANOVAs, for light conditions, timing of exposure, duration of exposure, and brain area) were performed on each EEG band. Results indicated an alerting effect of short exposure to monochromatic blue light at midday and in the evening, which was demonstrated by a decrease in lower frequency bands (alpha1, delta, and theta, respectively). Long exposure to blue light may have a reverse effect, especially in the morning and at midday, when increases in lower frequency bands (theta in the morning and theta and alpha1 at midday) were observed. It can be concluded that the daytime effect of monochromatic

blue light on EEG activity depends on timing and duration of exposure.

blue light, timing,

duration, EEG bands

\section{INTRODUCTION}

An alerting effect of monochromatic blue light has been consistently reported in recent research. Earlier experiments searching for this effect on brain activity applied blue light at night-time. For example, Lockley et al. (2006) reported that $6.5 \mathrm{hr}$ exposure to monochromatic blue light $(460 \mathrm{~nm})$ administered $9.25 \mathrm{hrs}$ before wake time, in comparison to green light $(555 \mathrm{~nm})$ of the same photon density $(2.8 \times 1.013$ $\mathrm{ph} / \mathrm{cm}^{2} / \mathrm{s}$ ), increased electroencephalography (EEG) power density in the high-alpha range, decreased EEG power density in the deltatheta range, reduced subjective sleepiness, and improved performance.
Another study demonstrated that 6-hr exposure to blue light, as compared to dim broad spectrum white light of the same level of luminance $\left(7 \mathrm{~cd} / \mathrm{m}^{2}\right)$ administered at night (23:30-05:30), suppressed EEG delta and theta activity, reduced slow eye movements, and shortened reaction time (Phipps-Nelson, Redman, Schlangen, \& Rajaratnam, 2009). Forty-five min of night-time exposures (00:00-03:45) to both

Corresponding author: Irena Iskra-Golec, SWPS University of Social Sciences and Humanities, Faculty in Poznań, Poland. E-mail: upiskra@cyf-kr.edu.pl 
short- $(470 \mathrm{~nm})$ and long-wavelength $(630 \mathrm{~nm})$ light of two levels of intensity (10 and 40 lux) preceded by $1 \mathrm{hr}$ of darkness significantly increased beta and reduced alpha EEG power (Figueiro, Bierman, Plitnick, \& Rea, 2009). In a further study by this group, application of the same light parameters and night-time exposure increased EEG beta power, reduced subjective sleepiness, and increased positive affect (Plitnick, Figueiro, Wood, \& Rea, 2010). In brief, the night-time studies applied relatively long durations of exposures to monochromatic blue light as well as to a range of dim light intensities and wave lengths in both experimental and control conditions.

There is also increasing evidence of an alerting effect of blue light administered during the day. Evening exposure (21:30-23:30) to blue light $(460 \mathrm{~nm})$, compared to green light $(550 \mathrm{~nm})$ of equal photon densities $\left(2.8 \times 1,013\right.$ photons $\left./ \mathrm{cm}^{-2} / \mathrm{s}^{-1}\right)$, resulted in a reduction in EEG slow-wave activity in the first cycle of subsequent sleep and in shortening rapid-eye movement (REM) sleep in the first two sleep cycles. This was interpreted as being an alerting effect after blue light exposure that persisted into the sleep episode (Münch et al., 2006). Earlier daytime exposure ( $7 \mathrm{hr}$ after habitual awakening time and lasting $48 \mathrm{~min}$ ) to red light $(630 \mathrm{~nm})$ and to blue light $(470 \mathrm{~nm})$ of the same level of illuminance $\left(18.9 \mu \mathrm{W} / \mathrm{cm}^{2}, 40 \mathrm{lux}\right)$ resulted in significant reductions in alpha, alpha-theta, and theta EEG activity under red light when compared to darkness. However, the decrease in alpha and alpha-theta power in the blue light condition was nonsignificant (Sahin \& Figueiro, 2013). Daytime studies tended to use similar monochromatic blue light intensities as well as wavelengths, but shorter durations of exposures in comparison to night-time studies.

A series of experiments comparing modulation of brain responses (assessed by functional magnetic resonance imaging [fMRI]) by monochromatic light while performing auditory, cognitive, and emotional tasks (Vandewalle et al., 2011; Vandewalle, Gais, et al., 2007; Vandewalle, Schmidt, et al., 2007; Vandewalle et al., 2010) were conducted in the afternoon, in the evening, and at the beginning of the night. The daytime exposures lasting from 40-60 s to $18 \mathrm{~min}$ elicited stronger brain responses to blue light ( $473 \mathrm{~nm}$ or $480 \mathrm{~nm}$ ) when compared to green light $(527 \mathrm{~nm})$ and violet light $(430 \mathrm{~nm})$ of the same irradiance level $\left(1,013\right.$ photons $\left./ \mathrm{cm}^{2} / \mathrm{s}\right)$. These light-induced moderations during auditory cognitive tasks were demonstrated in alertness-related subcortical structures as well as in long term memory and emotionrelated areas. These daytime studies, applying fMRI and positron emission tomography (PET), used shorter durations of exposures, very low photon densities, and earlier timing of exposures than night-time and daytime studies applying EEG recordings.

The studies demonstrating alerting effects of monochromatic blue light on brain activity applied a variety of timings and durations of exposures as well as light parameters. Therefore, it is difficult to draw firm conclusions on when the timing of exposure should be or how long and how intensive blue light exposure needs to be in order to produce an alerting effect during the day. It has already been established that sensitivity of the human circadian timing system to light parallels the 24-hr rhythm of alertness/sleepiness (Minors, Waterhouse, \& Wirz-Justice, 1991). This rhythm is modulated by an interaction of homeostatic sleep pressure (increasing from awakening) and circadian oscillations driven by the circadian pacemaker promoting optimal levels of alertness during the day and consolidated sleep at night (Borbely, 1982). As a result, there are periods of increased sleepiness as well as sensitivity to light that occur several times during the 24-hr day. The first such period occurs in the early morning due to sleep inertia (Akerstedt \& Folkard, 1997). The next one, the so-called "post-lunch dip" (Monk, 2005), appears in the early afternoon when the circadian drive for alertness is not strong enough to counteract the increased homeostatic sleep pressure (Cajochen, Blatter, \& Wallach, 2004; Edgar, Dement, \& Fuller, 1993). The last period occurs in the evening and into the night when both homeostatic and circadian processes promote sleepiness (Akerstedt \& Folkard, 1997).

To sum up, in response to questions raised by the nature of previous blue light research, the aim of this study was to investigate the effects of short and long durations of daytime exposure to monochromatic blue light at three different times of the day. The alerting effects of blue light on brain EEG activity have already been demonstrated in the research studies cited, but more precise analyses will be possible when different timings and durations of exposure to light of the same parameters are compared. We were interested in its effect on broad-band brain EEG activity during a waking day. It was hypothesized that (a) daytime exposure to blue light increases alertness which will be marked by corresponding changes of spectral EEG power, namely, decreases in low wave activity (delta to high alpha) and increases in higher frequencies (beta) at times of increased sensitivity to light/daytime sleepiness; and (b) these alerting effects may depend on the duration and timing of exposure.

\section{MATERIALS AND METHODS}

\section{Participants}

Thirty healthy, male student volunteers, aged $19-28$ years $\left(M_{\text {age }}=20.5\right.$ years; $S D=3.34$ years) participated in the study. All subjects were paid and the following inclusion criteria were applied: a regular sleep-wake schedule (habitual sleep timing 22:00-23:30 to 07:00-08:00), intermediate chronotypes as measured by the Morningness-Eveningness Questionnaire (Horne \& Ostberg, 1976), right-handedness, no experience of shift work or travel to other time zones within 2 months before the experiment, normal vision, no history of head injury or neurological disorders, no sleep-related disorders, and no current taking of drugs. Prior to the experiment, the participants were made familiar with the experimental procedure and the tasks to be performed during practice sessions. Each participant provided written informed consent. The participants were asked to keep their usual and stable timing of sleep two weeks before the experiment and while participating in the experiment and to refrain from alcohol and caffeine intake during the experiment. All individuals had to participate in all the sessions in different sequences (every day and one session per day). For control purposes, participants' sleep timing and sleep quality were assessed using the Pittsburgh Sleep Quality Index (Buysse, Reynolds, Monk, Berman, \& Kupfer, 1989) every day. 


\section{Experimental procedure}

A counterbalanced repeated-measures design was applied. There were two light conditions differing in wavelength, namely, monochromatic blue LED light (peak at $460 \mathrm{~nm}$ ) of irradiance equal to $1.1902 \mathrm{E}^{-1} \mu \mathrm{W} /$ $\mathrm{cm}^{2}$ and polychromatic white LED light of 6.5 lux intensity. Both light conditions were comparable in luminance level on room surfaces at eye level while sitting $\left(0.677 \mathrm{~cd} / \mathrm{m}^{2}-0.762 \mathrm{~cd} / \mathrm{m}^{2}\right)$. Measurements of actual lighting conditions were performed using an Ocean Optics HR400 high-resolution spectrometer (Välisuo, Harju, \& Alander, 2010) with an optical sensor set at a solid angle of $2^{*} \mathrm{Pi}$ sr (Field of View $=180^{\circ}$ ). The experiment took place in a light laboratory with no windows and with all surfaces (including the floor) coloured white. The light laboratory was equipped with a ceiling mounted, automatically controlled light system with four luminaires containing LED emitting monochromatic blue light $(460 \mathrm{~nm}+/-20 \mathrm{~nm}$ of wavelength and light intensity from 0 to $28 \mu \mathrm{W} / \mathrm{cm}^{2}$ ) or polychromatic white light (light intensity from 0 to 500 lux). Each luminaire included a Barrisol diffusor which diffused light evenly.

There were three experimental sessions (timings of exposure) within a 16-hr daytime period (07:00-12:20; 12:20-17:40, and 17:4023:00) and two durations of exposure (measurements were taken after $30 \mathrm{~min}$ and after $4 \mathrm{hr}$ exposure). One participant was examined during one session and each participant took part in each session (one session per day) in both light conditions in a random order. There were purification periods (almost complete darkness) - $15 \mathrm{~min}$ long at the beginning and $5 \mathrm{~min}$ long at the end of each session. A semi-constant routine protocol was applied to keep stable experimental conditions and activity of participants. There was a constant level of noise, humidity, and ambient temperature $\left(20^{\circ} \mathrm{C}\right)$. During the experimental sessions, the participants remained seated at a desk and were permitted to read or listen to the music during the periods free from measurements.

\section{Measures}

EEG measurements were taken two times during each session. EEG data were recorded with Mitsar 19-channel EEG 201 equipment (Plechawska-Wójcik \& Kaczorowska, 2016) set to $250 \mathrm{~Hz}$ sampling rate. An additional electrode was placed over a participant's left eye for further blink correction and two more electrodes were used for offline linked mastoid reference. All impedances were kept in a recommended range, below $5 \mathrm{k} \Omega$. Preprocessing was carried out using EEGLab toolbox version 13 (Fratantoni, DeLaRosa, Didehbani, Hart, \& Kraut, 2017). The signal was filtered with $1 \mathrm{~Hz}$ high-pass and $40 \mathrm{~Hz}$ low-pass filters. Ocular correction was performed using the conventional recursive least squares (CRLS) regression method (Wilson, He, \& Russell, 2004). Whole recordings were divided into 2 -s epochs, overlapping for $0.5 \mathrm{~s}$. The epochs which still contained artifacts (absolute signal amplitude $>70 \mu \mathrm{V}$ ) were removed. For spectral power estimation, the fast Fourier transform was applied (Wilson et al., 2004). The obtained spectral power values were aggregated into delta $(1-3 \mathrm{~Hz})$, theta $(4-7 \mathrm{~Hz})$, alpha1 $(8-10 \mathrm{~Hz})$, alpha2 $(10-12 \mathrm{~Hz})$, and beta $(15-30 \mathrm{~Hz})$ bands. One of the typical divisions found in the literature (Besserve et al., 2007; Yu et al., 2013) was used to make the alpha and beta more dissociated from each other in terms of functional significance as the transition be- tween the bands is to some extent arbitrary and the neighboring ranges can be moderately correlated (Lorig \& Schwartz, 1989).

\section{Statistical Analysis}

A four-factor analysis of variance (ANOVA) with repeated-measures (with the Bonferroni adjustment) was performed on the results of each EEG frequency band separately using SPSS 23.0. The first factor was light condition (LC). There were two light conditions: polychromatic white light (PWL) and monochromatic blue light (MBL). The second factor was timing of exposure (TE) with three levels (morning, midday, and evening sessions of exposure). The third factor was duration of exposure (DE) with two levels of duration: the short one after $30 \mathrm{~min}$ of exposure to LC (first measurement time within each session) and long duration after 4 hrs of exposure to LC (the second measurement time within each session). The fourth factor was the brain region of interest (ROI). Electrode choice and placement were made in accordance with typical procedures reported in earlier EEG-based research. Therefore, in accord with studies described in the literature (e.g., Gumenyuk et al., 2001; Kiehl, Bates, Laurens, Hare, \& Liddle, 2006), we distinguished ten different brain areas in several configurations to reflect the explorative nature of the present analyses. The following ROIs were used as measurement sites: left frontal lobe (Fp1, F7, F3), right frontal lobe (Fp2, F4, F8), motor cortex (C3, Cz, C4), left temporal lobe (T3, T5), right temporal lobe (T4, T6), anterior temporal lobes (T3, T4), posterior temporal lobes (T5, T6), parietal lobe (P3, Pz, P4), occipital lobe $(\mathrm{O} 1, \mathrm{O} 2)$, and midline central $(\mathrm{Fz}, \mathrm{Cz}, \mathrm{Pz})$. Two-tailed paired $t$ tests were used to further compare the main effects and interactions when significant effects were detected by an ANOVA.

\section{RESULTS}

\section{Light Conditions and Duration of Exposure Effects by Brain Region}

\section{EEG DELTA SPECTRAL POWER BAND}

Three-way interaction effects $(\mathrm{LC} \times \mathrm{DE} \times \mathrm{ROI})$ on EEG delta were observed, $F(9,261)=2.07, p=.032, \mathrm{n}^{2}=.067$. This incorporated effects for the left frontal, $F(1,29)=4.35, p=.046, \mathrm{n}^{2}=.130$, right temporal, $F(1,29)=26.87, p<.001, \mathrm{n}^{2}=.481$, anterior temporal, $F(1,29)=14.26$, $p=.001, \mathrm{n}^{2}=.330$, posterior temporal, $F(1,29)=7.63, p=.010, \mathrm{n}^{2}=$ .208 , and occipital, $F(1,29)=4.25, p=.048, \mathrm{n}^{2}=.128$, brain regions (see Table 1). Compared to short exposure to PWL, there was a significant decrease in delta activity after short exposure to MBL in the occipital lobe region, $t(29)=2.41, p=.022$. Long exposure to MBL, compared to long exposure to PWL, resulted in a significant increase in delta activity in the anterior temporal lobes, $t(29)=-2.19, p=.036$. In comparison to short exposure, long exposure to PWL resulted in a statistically significant decrease in the delta band in the left frontal region, $t(29)=2.09, p=.046$, the right-, anterior-, and posterior temporal regions, $t(29)=5.18, p=.001, t(29)=3.78, p=.001$, and $t(29)=$ $2.76, p=.010$, respectively, as well as in the occipital brain areas, $t(29)$ $=2.06, p=.048$. There was no effect of timing of exposure to MBL on EEG delta activity. 


\begin{tabular}{|c|c|c|c|c|c|c|}
\hline LC: & DE: & Frontal & Temporal & Temporal & Temporal & Occipital \\
\hline & 1 & $\begin{array}{c}48.54 \\
(.34)\end{array}$ & $\begin{array}{c}50.17 \\
(.26)\end{array}$ & $\begin{array}{c}50.94 \\
(.28)\end{array}$ & $\begin{array}{c}52.50 \\
(.26)\end{array}$ & $\begin{array}{c}53.27 \\
(.30)\end{array}$ \\
\hline & 2 & $\begin{array}{l}48.06 \\
(.31)\end{array}$ & $\begin{array}{l}49.14 \\
(.25)\end{array}$ & $\begin{array}{l}50.08 \\
(.26)\end{array}$ & $\begin{array}{c}52.08 \\
(.23)\end{array}$ & $\begin{array}{c}53.00 \\
(.26)\end{array}$ \\
\hline & 1 & $\begin{array}{l}48.29 \\
(.32)\end{array}$ & $\begin{array}{c}49.94 \\
(.27)\end{array}$ & $\begin{array}{l}50.56 \\
(.27)\end{array}$ & $\begin{array}{c}52.33 \\
(.21)\end{array}$ & $\begin{array}{c}52.93 \\
(.25)\end{array}$ \\
\hline & 2 & $\begin{array}{l}48.39 \\
(.36)\end{array}$ & $\begin{array}{c}49.74 \\
(.36)\end{array}$ & $\begin{array}{l}50.65 \\
(.31)\end{array}$ & $\begin{array}{c}52.42 \\
(.32)\end{array}$ & $\begin{array}{c}53.11 \\
(.28)\end{array}$ \\
\hline
\end{tabular}

Note. Light Conditions (LC); Polychromatic White Light (PWL); Monochromatic Blue Light (MBL); Short (1), Long (2) Duration of Exposure (DE). Standard Deviation (in brackets)

\section{TABLE 2.}

Mean Values of EEG Theta Spectral Power Band

in Two Light Conditions in Three Brain Regions

\begin{tabular}{ccccc}
\hline \multicolumn{2}{c}{ EEG band: } & \multicolumn{3}{c}{ Theta $(4-7 \mathrm{~Hz})$} \\
\hline \multirow{2}{*}{ LC: } & DE: & $\begin{array}{c}\text { Motor } \\
\text { Cortex }\end{array}$ & $\begin{array}{c}\text { Right } \\
\text { Temporal }\end{array}$ & $\begin{array}{c}\text { Midline } \\
\text { Central }\end{array}$ \\
\hline & \multirow{2}{*}{1} & 48.74 & 45.19 & 48.86 \\
& & $(.31)$ & $(.34)$ & $(.34)$ \\
PWL & & 48.98 & 44.78 & 49.14 \\
& 2 & $(.33)$ & $(.38)$ & $(.31)$ \\
& & 48.53 & 44.86 & 48.68 \\
& 1 & $(.32)$ & $(.36)$ & $(.32)$ \\
MBL & & 49.02 & 45.10 & 49.18 \\
& 2 & $(.30)$ & $(.39)$ & $(.36)$
\end{tabular}

Note. Light Conditions (LC); Polychromatic White Light (PWL); Monochromatic Blue Light (MBL); Short (1), Long (2) Duration of Exposure (DE). Standard Deviation (in brackets).

\begin{tabular}{|c|c|c|c|c|}
\hline \multicolumn{5}{|c|}{$\begin{array}{l}\text { TABLE } 3 . \\
\text { Mean Values of EEG Theta Spectral Power Band } \\
\text { in Two Light Conditions in Three Brain Regions } \\
\text { in Different Timing of Exposure }\end{array}$} \\
\hline \multirow{2}{*}{\multicolumn{2}{|c|}{ EEG band: }} & \multicolumn{3}{|c|}{ Theta $(4-7 \mathrm{~Hz})$} \\
\hline & & \multicolumn{3}{|c|}{ Timimg of exposure (TE): } \\
\hline LC: & DE: & $\begin{array}{c}\text { Morning } \\
(7.00-12.20) \\
\end{array}$ & $\begin{array}{c}\text { Midday } \\
(12.20-17.40)\end{array}$ & $\begin{array}{c}\text { Evening } \\
(17.40-23.00)\end{array}$ \\
\hline \multirow{2}{*}{ PWL } & 1 & $\begin{array}{l}46.93 \\
(.36)\end{array}$ & $\begin{array}{l}47.05 \\
(.35)\end{array}$ & $\begin{array}{l}47.49 \\
(.34)\end{array}$ \\
\hline & 2 & $\begin{array}{l}47.28 \\
(.36)\end{array}$ & $\begin{array}{l}46.99 \\
(.38)\end{array}$ & $\begin{array}{l}47.30 \\
(.31)\end{array}$ \\
\hline \multirow{2}{*}{ MBL } & 1 & $\begin{array}{l}46.73 \\
(.34)\end{array}$ & $\begin{array}{l}46.86 \\
(.33)\end{array}$ & $\begin{array}{l}47.07 \\
(.28)\end{array}$ \\
\hline & 2 & $\begin{array}{l}47.05 \\
(.30)\end{array}$ & $\begin{array}{l}47.67 \\
(.37)\end{array}$ & $\begin{array}{l}47.19 \\
(.34)\end{array}$ \\
\hline
\end{tabular}

\section{EEG THETA SPECTRAL POWER BAND}

A significant 3-way $(\mathrm{LC} \times \mathrm{DE} \times \mathrm{ROI})$ interaction, $F(9,261)=2.03$, $p=.037, \mathrm{n}^{2}=.065$, was found for three brain areas, namely, the motor cortex, $F(1,29)=4.32, p=.047, \mathrm{n}^{2}=.130$, the right temporal region, $F(1,29)=6.49, p=.016, \mathrm{n}^{2}=.183$, and the midline central region, $F(1$, 29) $=5.10, p=.032, \mathrm{n}^{2}=.149$ (see Table 2$)$.

Short exposure to MBL, compared to short exposure to PWL, resulted in a statistically significant decrease in theta activity in the motor cortex, $t(29)=2.08, p=.047$. In comparison to short exposure to MBL, long exposure to MBL increased theta activity in the motor cortex, $t(29)=9.00, p=.001$, and at midline central brain sites, $t(29)=9.19, p$ $=.001$. There was an increase in theta in the motor cortex, $t(29)=8.65$, $p=.047$, and the midline central region, $t(29)=8.24, p=.032$, following long exposure to PWL compared to short exposure to PWL, while in the right temporal lobes, there was a decrease, $t(29)=6.20, p=.016$. No statistically significant differences in EEG theta activity were found between MBL and PWL treatments for longer exposures.

No statistically significant interactions of light conditions and duration of exposure on alpha1, alpha2, and beta EEG bands were observed.

\section{Light Conditions, Duration of Exposure, and Timing of Exposure Effects}

\section{EEG THETA SPECTRAL POWER BAND}

A significant interaction between LC, DE, and TE was found for the EEG theta band, $F(2,58)=3.35, p=.042, \mathrm{n}^{2}=.104$ (see Table 3).

In the morning, long MBL exposure, compared to short MBL exposure, was reflected by increased theta activity, $t(29)=-2.09, p=.046$. A similar effect was observed for PWL, $t(29)=-2.18, p=.037$ (see Figure 1). At midday, long exposure to MBL produced significantly

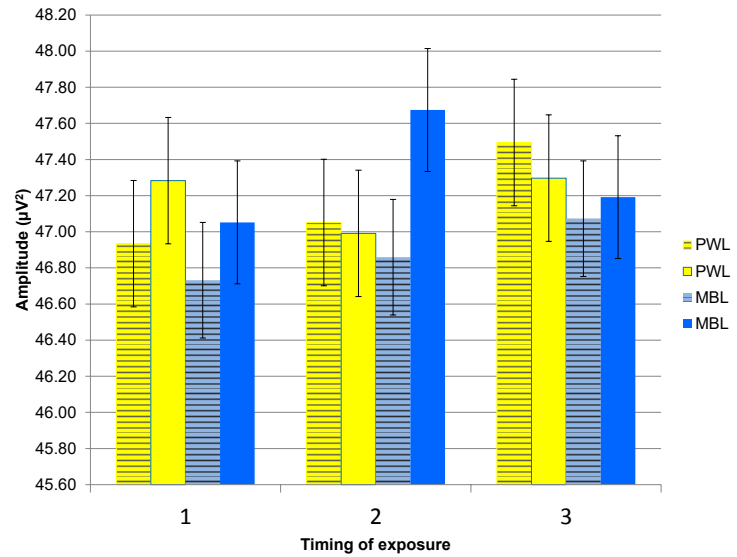

FIGURE 1.

EEG theta spectral power band mean values and SEs (vertical bars) after short exposure (striped pillar) and long exposure (filled pillar) in three timings of exposure (1-morning, 2-midday, 3-evening) in polychromatic white light (PWL, yellow pillars) and monochromatic blue light (MBL, blue pillars). 
higher values of theta power than both long exposure to PWL, $t(29)$ $=-2.18, p=.037$, and short exposure to MBL, $t(29)=-3.42, p=.002$. In comparison to short exposures to $\mathrm{PWL}$, short exposures to MBL resulted in significant decreases in theta in the evening, $t(29)=2.04, p$ $=.050$, but nonsignificant lower values at the other times of day.

\section{EEG ALPHA1 SPECTRAL POWER BAND}

A significant 3-way interaction $(\mathrm{LC} \times \mathrm{DE} \times \mathrm{TE})$ effect on the $\mathrm{EEG}$ alphal band was observed, $F(2,58)=3.72, p=.030, \mathrm{n}^{2}=.114$. At midday, compared to short exposure to PWL, short exposure to MBL resulted in a significant decrease in alpha1, $t(29)=2.09, p=.045$ (see Table 4).

In addition, compared to short MBL exposure, longer exposure to MBL at midday resulted in a significant increase in alpha1, $t(29)=5.52$,

\begin{tabular}{|c|c|c|c|c|}
\hline \multicolumn{5}{|c|}{$\begin{array}{l}\text { TABLE } 4 . \\
\text { Mean Values of EEG Alpha1 Spectral Power Band } \\
\text { in Two Light Conditions in Three Brain Regions } \\
\text { in Different Timing of Exposure }\end{array}$} \\
\hline \multirow{2}{*}{\multicolumn{2}{|c|}{ EEG band: }} & \multicolumn{3}{|c|}{ Alphal $(8-10 \mathrm{~Hz})$} \\
\hline & & \multicolumn{3}{|c|}{ Timimg of exposure (TE): } \\
\hline LC: & DE: & $\begin{array}{c}\text { Morning } \\
(7.00-12.20)\end{array}$ & $\begin{array}{c}\text { Midday } \\
(12.20-17.40)\end{array}$ & $\begin{array}{c}\text { Evening } \\
(17.40-23.00)\end{array}$ \\
\hline \multirow{2}{*}{ PWL } & 1 & $\begin{array}{l}47.14 \\
(.58)\end{array}$ & $\begin{array}{l}47.19 \\
(.58)\end{array}$ & $\begin{array}{l}47.33 \\
(.57)\end{array}$ \\
\hline & 2 & $\begin{array}{l}47.38 \\
(.56)\end{array}$ & $\begin{array}{l}47.00 \\
(.59)\end{array}$ & $\begin{array}{l}47.22 \\
(.56)\end{array}$ \\
\hline \multirow{2}{*}{ MBL } & 1 & $\begin{array}{l}47.01 \\
(.56)\end{array}$ & $\begin{array}{l}46.76 \\
(.58)\end{array}$ & $\begin{array}{l}46.93 \\
(.53)\end{array}$ \\
\hline & 2 & $\begin{array}{l}47.10 \\
(.52)\end{array}$ & $\begin{array}{l}47.31 \\
(.56)\end{array}$ & $\begin{array}{l}46.83 \\
(.54)\end{array}$ \\
\hline
\end{tabular}

Note. Light Conditions (LC); Polychromatic White Light (PWL); Monochromatic Blue Light (MBL); Short (1), Long (2) Duration of Exposure (DE), Timing of Exposure (TE), Standard Deviation (in brackets).

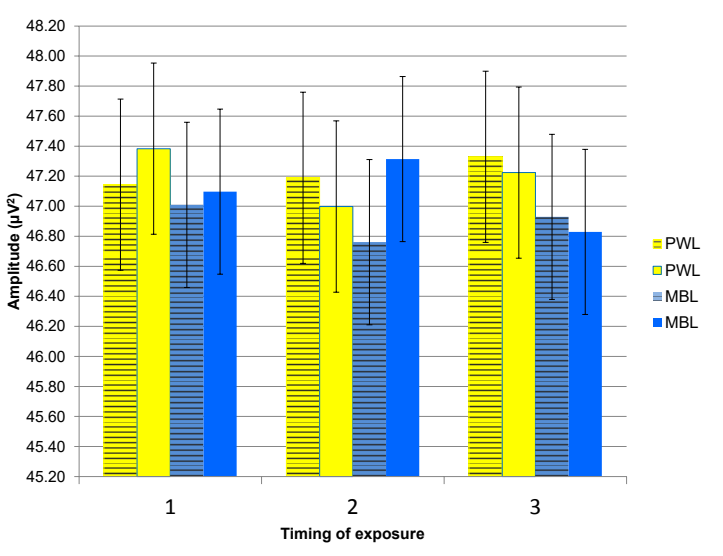

FIGURE 2.

EEG alpha 1 spectral power band mean values and SEs (vertical bars) after short exposure (striped pillar) and long exposure (filled pillar) in three timings of exposure (1-morning, 2-midday, 3-evening) in polychromatic white light (PWL, yellow pillars) and monochromatic blue light (MBL, blue pillars). $p=.005$. Duration of exposure effects on the alphal band were not significant under PWL conditions at any time during the waking day.

No statistically significant interaction effects on alpha2 and beta bands were observed.

\section{DISCUSSION}

The aim of this study was to investigate the effects of timing and duration of daytime exposure to MBL on a range of EEG frequency bands (delta, theta, alpha1, alpha2, and beta). It was hypothesized that alerting effects of daytime exposure to MBL would depend on its timing and duration. EEG activity has been utilized as an index or proxy for conscious alertness levels (e.g., Wyczesany, Kaiser, \& Coenen, 2008) and, consistent with existing neuropsychological research, the decreases in delta (locally), and theta and alphal (globally) after short duration exposure to MBL in this study may mean an increase in alertness. The lower frequency EEG rhythms (up to alpha) have been reported to be more sensitive to changes in vigilance than the higher frequency rhythms (beta, gamma) (Kubicki, Rieger, Busse, \& Barckow, 1970; Wyczesany et al., 2008). Drowsiness has been marked by noticeable changes in low theta band amplitude, whereby increased low theta power was associated with lower levels of arousal, vigilance, or alertness (e.g., Makeig, Jung, \& Sejnowski, 2000). Increases in delta and theta waves have correlated positively with subjective sleepiness (Strijkstra, Beersma, Drayer, Halbesma, \& Daan, 2003) and fatigue (Lal \& Craig, 2002). Furthermore, neuroimaging studies demonstrated that brain areas involved in the effect of MBL included wake promoting subcortical structures in the brain stem, hypothalamus, and thalamus related with alertness (Vandewalle, Gais, et al., 2007; Vandewalle, Maquet, \& Dijk, 2009; Vandewalle, Schmidt, et al., 2007).

In the present study, an alerting effect of light dependent on light conditions and exposure duration was found locally in several brain regions with respect to EEG delta and theta bands. The effect of light on EEG delta activity was found locally in five brain regions (left frontal, right-, anterior-, and posterior temporal, and occipital lobes). In comparison to short exposure to PWL, similar MBL exposure decreased delta activity in the occipital lobes. Short exposures to PWL were reflected in decreased delta activity in the remaining four brain regions. EEG theta band was modulated by light conditions and duration of exposure in several brain regions including motor cortex, right temporal, and midline central areas. Significant decrease in theta activity after short exposure to MBL when compared to PWL appeared locally in the motor cortex region. Long exposures to both MBL and PWL resulted in increase of theta activity in the remaining two brain areas (i.e., right temporal and midline central).

In addition, global effects on EEG theta band and alphal band were observed for all brain regions, dependent upon light conditions, timing, and duration of exposure. EEG theta and alphal activity were moderated jointly by light conditions as well as timing and duration of exposure to MBL, irrespective of brain area. There were differential effects for time of day of light exposure. Significant decreases in theta activity were observed following short exposure to MBL in the 
evening but, for alpha1, activity decreased at midday. In contrast to short exposures, long exposures to MBL significantly increased theta in the morning and at midday and increased alphal activity at midday. The decrease in alphal activity as a result of short exposure to MBL at midday (independently of brain region) disagrees with the findings of Sahin and Figureiro's (2013) study which reported no significant alerting effects of 48 min exposures to MBL on alpha and alpha-theta activity. This may result from different timings and durations of exposure as well as MBL light parameters (especially light intensity) applied in the different studies.

One intriguing finding of the current study is an increase in both theta (reflective of increased sleepiness) and alphal (typically representative of wakefulness) activity after long exposure to MBL at midday (close to the post-lunch dip period). This apparently contradictory effect may be explained in terms of sleep and sleepiness/alertness models (Akerstedt \& Folkard, 1997; Borbely, 1982). That is, the circadian drive for alertness, augmented possibly by long MBL exposure, is not sufficiently strong at that time of day to counteract an increasing homeostatic sleep pressure. Moreover, findings from research on circadian effects of light (resetting the timing of the circadian pacemaker) show that increased sleep homeostatic pressure, as a result of deficient sleep, attenuated the alertness that should be consequent to the circadian effect (Burgess, 2010).

While corroborating earlier research to some extent, the results of this study require replication to confirm the observed effects, perhaps focusing on those brain areas considered to be most responsive to the light treatment and indexing subjective alertness and cognitive performance. In addition, the homogeneity of the present group of subjects with regard to sex and age tends to limit the possibility of broader generalization of the conclusions and would need to be addressed in future research. Having said this, the systematic approach taken to examining monochromatic blue light effects during the waking day appears to be a robust procedure.

Overall, it may be concluded that an alerting effect of daytime exposure to monochromatic blue light was observed for lower frequency EEG bands including delta (locally), theta (locally and globally), and alphal (globally), and that this alerting effect depended on duration and timing of exposure. The examination of the literature to date revealed that the potential alerting effects of duration and timing of daytime exposure to monochromatic blue light of the same parameters has not been studied yet. From a practical and human performance perspective, future research might be directed at trying to establish the underlying mechanisms which prevent alerting effects of long exposure to monochromatic blue light at midday and in the morning.

\section{ACKNOWLEDGEMENTS}

This research project was supported by a grant from the National Science Centre Poland (project no. DEC 2013/09/B/HS6/02646).

\section{DECLARATION OF INTEREST}

The authors declare no conflict of interests.

\section{REFERENCES}

Akerstedt, T., \& Folkard, S. (1997). The three-process model of alertness and its extension to performance, sleep latency and sleep length. Chronobiology International, 14, 115-123. doi: 10.3109/07420529709001149 WWW

Besserve, M., Jerbi, K., Laurent, F., Baillet, S., Martinerie, J., \& Garnero, L. (2007). Classification methods for ongoing EEG and MEG signals. Biological Research, 40, 415-437. doi: 10.4067/ S0716-97602007000500005 WWW

Borbely, A. A. (1982). A two process model of sleep regulation. Human Neurobiology, 1, 195-204. doi: 10.1007/978-3-54029678-2_6166 |WWW

Burgess, H. J. (2010). Partial sleep deprivation reduces phase advances to light in humans. Journal of Biological Rhythms, 25, 460-468. doi: 10.1177/0748730410385544

Buysse, D. J., Reynolds, C. F., III., Monk, T. H., Berman, S. R., \& Kupfer, D. J. (1989). The Pittsburgh Sleep Quality Index: A new instrument for psychiatric practice and research. Journal of Psychiatric Research, 28, 193-213. doi: 10.1016/0165-1781(89)90047-4 |www|

Cajochen, C., Blatter, K., \& Wallach, D. (2004). Circadian and sleep-wake dependent impact on neurobehavioral function. Psychologica Belgica, 44, 59-80.

Edgar, D. M., Dement, W. C., \& Fuller, C. A. (1993). Effect of SCN lesions on sleep in squirrel monkeys: Evidence for opponent processes in sleep-wake regulation. Journal of Neuroscience, 13, 1065-1079. WWW

Figueiro, M. G., Bierman, A., Plitnick, B., \& Rea, M. S. (2009). Preliminary evidence that both blue and red light can induce alertness at night. BMCNeuroscience, 10:105. doi: 10.1186/14712202-10-105. WWW

Fratantoni, J. M., DeLaRosa, B. L., Didehbani, N., Hart J., Jr., \& Kraut, M. A. (2017). Electrophysiological correlates of word retrieval in traumatic brain injury. Journal of Neurotrauma, 34, 1017-1021. doi: 10.1089/neu.2016.4651 WW

Gumenyuk, V., Korzyukov, O., Alho, K., Escera, C., Schröger, E., Ilmoniemi, R. J., \& Näätänen, R. (2001). Brain activity index of distractibility in normal school-age children. Neuroscience Letters, 314, 147-150. doi: 10.1016/S0304-3940(01)02308-4 WWW

Horne, J. A., \& Ostberg, O. (1976). A self-assessment questionnaire to determine morningness-eveningness in human circadian rhythms. International Journal of Chronobiology, 4, 97-110. WWW

Kiehl, K. A., Bates, A. T., Laurens, K. R., Hare, R. D., \& Liddle, P. F. (2006). Brain potentials implicate temporal lobe abnormalities in criminal psychopaths. Journal of Abnormal Psychology, 115, 443-453. doi: 10.1037/0021-843X.115.3.443 WWW

Kubicki, S., Rieger, H., Busse, G., \& Barckow, D. (1970). Elektroenzephalographische Befunde bei schweren Schlafmittelvergiftungen [Electroencephalographic findings during heavy soporifics poisoning]. Zeitschrift für 
Elektroenzephalographie, Elektromyographie und Verwandte Gebiete, 1, 80-93.

Lal, S. K., \& Craig, A. (2002). Driver fatigue: Electroencephalography and psychological assessment. Psychophysiology, 39, 313-321. doi: 10.1017/S0048577201393095 WWW

Lockley, S. W., Evans, E. E., Scheer, F. A., Brainard, G. C., Czeisle, C. A., \& Aeschbach, D. (2006). Short-wavelength sensitivity for the direct effects of light on alertness, vigilance, and the waking electroencephalogram in humans. Sleep, 29, 161-168. doi: 10.1093/sleep/29.2.161 |WWW

Lorig, T. S., \& Schwartz, G. E. (1989). Factor analysis of the EEG indicates inconsistencies in traditional frequency bands. Journal of Psychophysiology, 3, 369-375. doi: 10.3758/BF03327318

Makeig, S., Jung, T. P., \& Sejnowski, T. J. (2000). Awareness during drowsiness: Dynamics and electrophysiological correlates. Canadian Journal of Experimental Psychology, 54, 266-273. WWW

Minors, D. S., Waterhouse, M., \& Wirtz-Justice, A. (1991). A human phase-response curve to light. Neuroscience Letters, 133, 36-40. doi: 10.1016/0304-3940(91)90051-T |WWW

Monk, T. H. (2005). The post-lunch dip in performance. Clinics in Sports Medicine, 24, e15-e23. doi: 10.1016/j.csm.2004.12.002 WWW

Münch, M., Kobialka, S., Steiner, R., Oelhafen, P., Wirtz-Justice, A., \& Cajochen, C. (2006). Wavelength-dependent effects of evening light exposure on sleep architecture and sleep EEG power density in men. American Journal of Physiology-Regulatory Integrative and Comparative Physiology, 290, R1421-R1428.

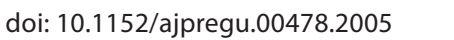

Phipps-Nelson, J., Redman, J. R., Schlangen, L. J., \& Rajaratnam, S. M. (2009). Blue light exposure reduces objective measures of sleepiness during prolonged nighttime performance testing. Chronobiology International, 26, 891-912. doi: 10.1080/07420520903044364 WWW

Plechawska-Wójcik, M., \& Kaczorowska, M. (2016). Performance analysis and optimal parameter selection for 300-based brain computer interface. Stidia Informatica, 37, 41-54.

Plitnick, B., Figueiro, M., Wood, B., \& Rea, M. (2010). The effects of red and blue light on alertness and mood at night. Lighting Research and Technology, 42, 449-458. doi: $10.1177 / 1477153509360887$

Sahin, L., \& Figueiro, M. G. (2013). Alerting effects of shortwavelength (blue) and long-wavelength (red) lights in the afternoon. Physiology and Behavior, 116-117, 1-7. doi: 10.1016/j. physbeh.2013.03.014 WWW
Strijkstra, A. M., Beersma, D. G., Drayer, B., Halbesma, N., \& Daan, S. (2003). Subjective sleepiness correlates negatively with global alpha $(8-12 \mathrm{~Hz})$ and positively with central frontal theta (4-8 $\mathrm{Hz}$ ) frequencies in the human resting awake electroencephalogram. Neuroscience Letters, 340, 17-20. doi: 10.1016/S03043940(03)00033-8

Välisuo, P., Harju, T., \& Alander, J. (2010). Reflectance measurement using digital camera and protecting dome with built in light source. Journal of Biobhotonics, 4: 559-564. doi: 10.1002/ jbio.201000113 $\overline{\mathrm{WWW}}$

Vandewalle, G., Archer, S. N., Wuillaume, C., Balteau, E., Degueldre, C., Luxen, A., ... Maquet, P. (2011). Effects of light on cognitive brain responses depend on circadian phase and sleep homeostasis. Journal of Biological Rhythms, 26, 249-259. doi: 10.1177/0748730411401736 WWW

Vandewalle, G., Gais, S., Schabus, M., Balteau, E., Carrier, J., Darsaud, A., ... Maquet, P. (2007). Wavelength-dependent modulation of brain responses to a working memory task by daytime light exposure. Cerebral Cortex, 17, 2788-2795. doi: $10.1093 /$ cercor/bhm007 WW

Vandewalle, G., Maquet, P., \& Dijk, D. J. (2009). Light as a modulator of cognitive brain function. Trends in Cognitive Sciences, 13, 429-438. doi: 10.1016/j.tics.2009.07.004

Vandewalle, G., Schmidt, C., Albouy, G., Sterpenich, V., Darsaud, A., Rauchs, G., ... Dijk, D. J. (2007). Brain responses to violet, blue, and green monochromatic light exposures in humans: Prominent role of blue light and the brainstem. PLOS ONE, 2 :e1247. doi: 10.1371/journal.pone.0001247 $\overline{\mathrm{WWW}}$

Vandewalle, G., Schwartz, S., Grandjean, D., Wuillaume, C., Balteau, E., Degueldre, C., ... Maquet, P. (2010). Spectral quality of light modulates emotional brain responses in humans. Proceedings of the National Academy of Sciences of the United States of America, 107, 19549-19554. doi: 10.1073/pnas.1010180107 WWW

Wilson, P., He, G., \& Russell, C. (2004). Removal of ocular artifacts from electro-encephalogram by adaptive filtering. Medical and Biological Engineering and Computing, 42, 407-412. WWW

Wyczesany, M., Kaiser, J., \& Coenen, A. (2008). Subjective mood estimation co-varies with spectral power EEG characteristics. Acta Neurobiologiae Experimentalis, 68, 180-192. | $\underline{\mathrm{WWW}}$

Yu, S., Li, P., Lin, H., Rohani, E., Choi, G., Shao, B., \& Wang, Q. (2013, September). Support vector machine based detection of drowsiness using minimum EEG features. In R. Bilof (Ed.), Proceedings of the IEEE International Conference on Social Computing (SocialCom) (pp. 827-835). New York, NY: The Institute of Electrical and Electronics Engineers. 